3-15-2018

Patient-Provider Communication Barriers and Facilitators to HIV and STI Preventive Services for Adolescent MSM

Celia B. Fisher

Adam L. Fried

Kathryn Macapagal

Brian Mustanski

Follow this and additional works at: https://research.library.fordham.edu/psych_facultypubs

Part of the Psychology Commons 
Patient-Provider Communication Barriers and Facilitators to HIV and STI Preventive Services for Adolescent MSM

\section{Celia B. Fisher, Adam L. Fried, Kathryn Macapagal \& Brian Mustanski}

AIDS and Behavior

ISSN 1090-7165

AIDS Behav

DOI 10.1007/s10461-018-2081-x

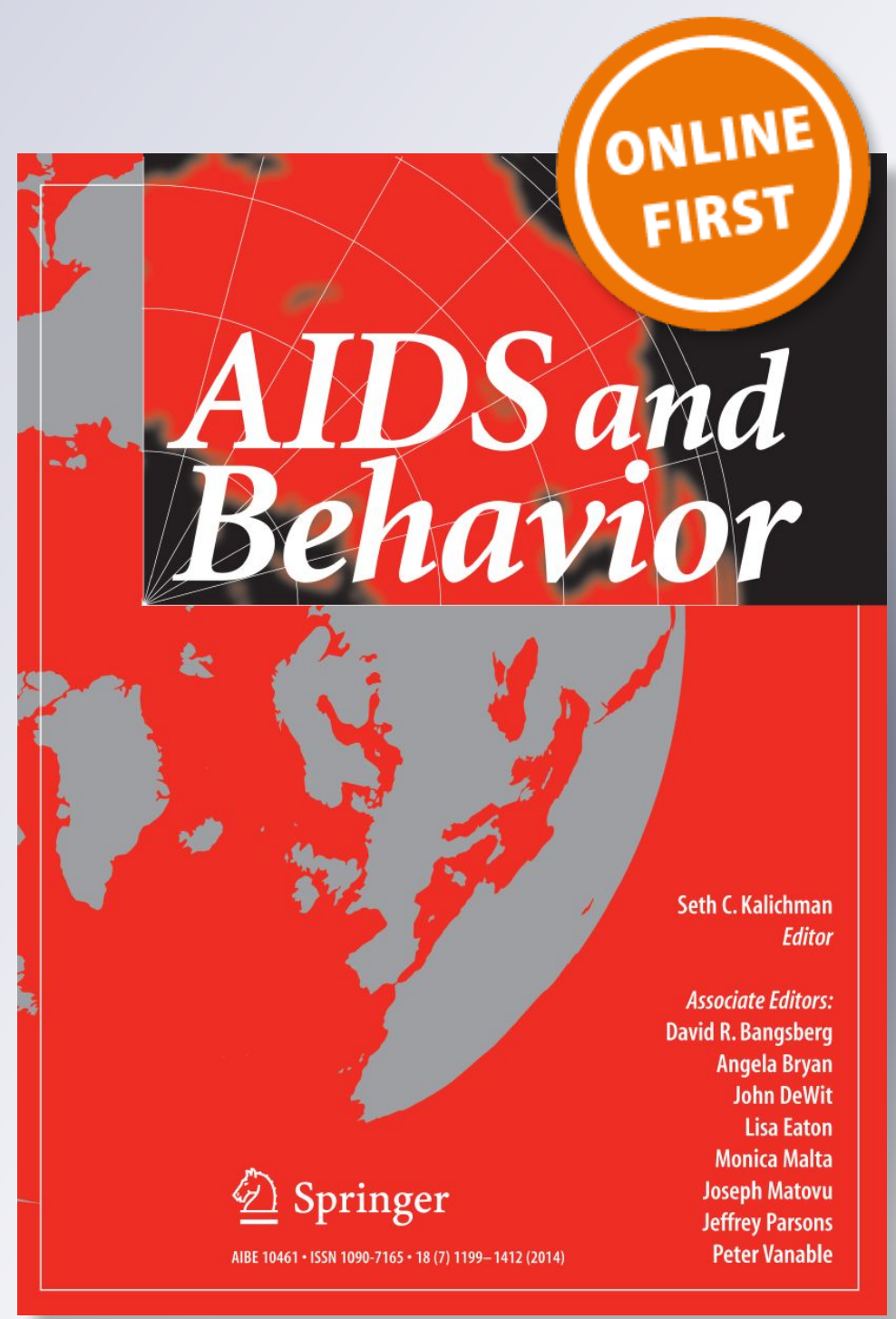

脰 Springer 
Your article is protected by copyright and all rights are held exclusively by Springer Science+Business Media, LLC, part of Springer Nature. This e-offprint is for personal use only and shall not be self-archived in electronic repositories. If you wish to selfarchive your article, please use the accepted manuscript version for posting on your own website. You may further deposit the accepted manuscript version in any repository, provided it is only made publicly available 12 months after official publication or later and provided acknowledgement is given to the original source of publication and a link is inserted to the published article on Springer's website. The link must be accompanied by the following text: "The final publication is available at link.springer.com". 


\title{
Patient-Provider Communication Barriers and Facilitators to HIV and STI Preventive Services for Adolescent MSM
}

\author{
Celia B. Fisher ${ }^{1} \cdot$ Adam L. Fried $^{2} \cdot$ Kathryn Macapagal $^{3} \cdot$ Brian Mustanski $^{3}$
}

๑) Springer Science+Business Media, LLC, part of Springer Nature 2018

\begin{abstract}
Adolescent males who have sex with males (AMSM) are at increased risk of contracting HIV/AIDS and other sexually transmitted infections (STIs). Healthcare providers are a critical source of HIV/STI prevention, yet little is known about AMSM patient-provider sexual health communications and services. To explore this issue, we surveyed a national sample of 198 AMSM 14-17 years. Four online psychometrically validated scales indicated over half the youth avoided communicating their sexual orientation and sexual health concerns to providers due to fear of heterosexist bias, concern their sexual health information would be disclosed to parents, and a general belief that sexual minority youth do not receive equitable treatment in health care settings. Youth who reported their physicians had initiated discussion about their sexual orientation were significantly more likely to have received HIV/STI preventive services and testing. Discussion includes the importance of medical training that meets the unique sexual health needs of AMSM.
\end{abstract}

Keywords Adolescent $\cdot$ HIV $\cdot$ Sexually transmitted infections $\cdot$ Healthcare $\cdot$ Men who have sex with men $\cdot$ MSM . Prevention $\cdot$ Stigma $\cdot$ Mistrust $\cdot$ Discrimination $\cdot$ Physician $\cdot$ Patient-provider communication

\section{Introduction}

Adolescent males who have sex with males (AMSM) continue to account for a disproportionally higher numbers of new HIV diagnoses and are more likely than their heterosexual peers to engage in high risk behaviors such as condomless sex and sex while intoxicated and to be diagnosed with a sexually transmitted infection (STI) [1-5]. In addition, young sexual minority males are less likely than older MSM to have received an HIV test and the least likely out of any age group to be linked to HIV care [6-14]. Despite research indicating that nearly half of gay and bisexual male high school students have had sexual intercourse [1] little is known about attitudinal and experiential factors facilitating

Celia B. Fisher

fisher@fordham.edu

1 Center for Ethics Education and Department of Psychology, Fordham University, Bronx, NY 10458, USA

2 Clinical Psychology Program, Midwestern University, Glendale, AZ, USA

3 Department of Medical Social Sciences, Northwestern University Feinberg School of Medicine, Chicago, IL, USA or impeding youth seeking and receiving health services for prevention, detection and treatment of HIV and STIs.

Barriers to receiving health care reported by older MSM include fear of sexual minority stigma or rejection by healthcare providers and failure of physicians to ask about sexual attractions [15-19]. The few studies that have begun to address adolescent sexual health services among sexual minorities have not focused on AMSM exclusively, but rather, pooled lesbian, gay and bisexual adolescent and young adult populations. This research suggests that while sexual minority relevant health information (including "safe sex" practices) has been found to be an important health concern among adolescent sexual minorities [20], a majority may postpone or avoid HIV testing and seeking other sexual health care services due to concerns their health care provider will not respect their confidentiality needs (including fear of being "outed" to guardians/parents) and negative judgment by health care providers about adolescent sexual identity, same sex sexual activity or sexual activity among teens $[9,17,19,21-24]$.

The aim of the current study was to identify factors facilitating and impeding HIV/STI preventive health services for 14-17 year old MSM. To date, attitudes and experiences influencing sexual health service utilization for AMSM in 
this age group has not been specifically examined. Based on the adult MSM and adolescent LGBTQ literature we hypothesized that physicians asking questions about youth's sexual attractions, being out to guardians about one's sexual orientation and sexual activity, and belief that sexual minority youth were treated equitably in health care settings would facilitate youth's HIV related communications with providers, receipt of HIV/STI preventive information and tools, and HIV testing. We further hypothesized that medical mistrust characterized by anticipated stigma and fear that providers would disclose information to parents and prior experiences with sexual minority discrimination in medical settings would be associated with reduced sexual health communications with providers and service utilization.

\section{Methods}

\section{Participants}

The sample of 198 AMSM ages 14-17 years was drawn from the Adolescent Scientific Access Project (ASAP!), one of a series of nationally-administered Internet-based surveys and focus groups on sexual behavior, social stigma and acceptance, healthcare experiences and attitudes, and attitudes toward participation in HIV prevention research among sexually active AMSM and transgender adolescents in the United States. The survey was conducted using LimeSurvey software over a 4-week period in early 2017. Participants were recruited through paid Facebook advertisements. Interested participants completed an 11-item screening questionnaire to determine eligibility. Inclusion criteria included identifying as male, having a male sex assigned at birth, 14-17 years old, living in the United States, being sexually attracted to males, reporting at least one lifetime male anal sex partner, and self-reporting HIV seronegative. Of the 1351 individuals who clicked on the ad and completed the online screener, 959 were screened as ineligible. The majority of those screened as ineligible either did not report an anal sexual encounter with another male or were over 18; this result was not unexpected, as the ad language describing the study was intentionally broad to reduce the occurrence of desirability effects and fraudulent responding. Of the 392 who completed the screener and met inclusion criteria, 178 did not complete the survey. There were no significant differences between completers and non-completers on any demographic or sexual behavior/risk variables. Of the 214 who completed the survey, 14 participants were eliminated because they failed attention and consistency validation checks $[25,26]$ and two were not included in the analysis because they identified as female, leaving a final sample of 198.

\section{Survey Items and Scales}

\section{Demographics, Sexual Behaviors and Attitudes and Family Acceptance}

Participants completed questions about race, ethnicity, living situation, year in school, housing, employment and SES as measured by guardian's education (youth were asked to identify a primary and secondary guardian). Sexuality questions focused on: (1) sexual identity, sexual history (number of lifetime sexual partners, gender of sexual partners); (2) sexual risk behaviors (sex without condoms and alcohol/ drug use before sex); (3) two 5-point Likert type questions on perceptions of HIV risk ("How likely do you think you are to become infected with HIV?" and "How much do you worry about getting infected with HIV?" [27] and (4) HIV/ STI prevention and testing services received from a doctor in the past year. Items also examined the extent to which youth were out to family members, their physician, and others and 5-point Likert type questions on family acceptance ("very accepting"- "very rejecting") of their sexual orientation and sexual activity with male partners [28].

\section{Sexual Health Care Attitudes and Experiences}

Eighteen items examining participant attitudes and experiences with sexual health care services were developed and refined from items included in our prior online focus group and surveys on healthcare experiences among bisexual female adolescents and attitudes toward HIV prevention research among adolescent and young adult MSM and transgender females $[21,29,30]$, review by a youth advisory council, and online piloting with a sample of 30 AMSM. All questions were introduced as follows: "The following questions ask about your experiences as an LGBTQ person receiving services from medical health care providers. A health care provider is a medical doctor, nurse practitioner, or other person providing medical care." Items reflected three sexual health care domains: (1) sexual health communications with providers about youth's sexual orientation, sex with male partners, HIV testing, discussion about PrEP, use of condoms in general and with male partners (6 items); (2) medical mistrust reflecting reluctance to discuss sexual health care needs due to concerns a provider would be critical of their sexual orientation or behaviors or disclose information to their parents ( 6 items); and (3) sexual minority discrimination experienced by the youth in a doctor's office, clinic or hospital in the form of negative comments, criticism, disapproval or poor treatment by a healthcare provider or staff member (6 items). All items were scored on a 5 -point Likert-type scale ( $1=$ never, $5=$ always $)$, 


\section{LGBTQ Health Equity Items}

As a complement to the six items describing personal experiences with sexual minority discrimination described above, we assessed general beliefs regarding systems level attitudes about equitable treatment for LGBTQ individuals in medical institutions and the medical profession. To accomplish this, we adapted 4 positively worded items from the Groupbased Medical Mistrust Scale [31] originally developed to assess general beliefs about racial equity and discrimination in health care settings. We modified the language to refer to LGBTQ persons (e.g., "LGBTQ people are treated the same as people of other groups by doctors and health care workers"). Items were scored on a 5-point Likert-type scale $(1=$ strongly disagree, $5=$ strongly agree $)$.

\section{Procedure}

Participants whose screener responses met inclusion criteria were contacted via e-mail and provided with a website address to access the full survey. Ineligible youth were redirected to a university registry for other available studies. The survey website included firewall protections with data encryption and the investigators received a Certificate of Confidentiality from the Department of Health and Human Services. Participants could end their participation at any time. All questions included the option "I prefer not to answer". Upon completion of the survey, participants were provided with a $\$ 30$ Visa gift card for their participation. The study was approved by the institutional review boards of Fordham University and Northwestern University.

\section{Analytic Plan}

Means, standard deviations, and percent agreement/disagreement were calculated for each item. Multivariate analysis of variance (MANOVAs), Chi squares, and correlations assessed effect of age and ethnicity on items and scales. This was followed by factor analyses (Varimax rotation using SPSS Version 19.0) and inter-item reliability calculations to construct scales representing the three sexual health care domains: sexual health communications, medical mistrust, and personal experiences with LGBTQ discrimination in health care settings. A second factor analysis and inter-item reliability was conducted on the four LGBTQ health equity items. Pearson product-moment correlations were conducted to assess associations between the scale scores and single items reflecting key demographics, disclosure to parents, sexual behaviors, and HIV/STI services. Linear multiple regression and binomial logistic regression were conducted to further examine the relative contribution of the scales and key demographic and sexual behavior items correlated with receipt of sexual health communication, HIV/STI services and HIV testing. The study was appropriately powered to answer the hypotheses. The total sample required to determine whether a correlation coefficient differs from zero for a 2-tailed test at the 0.05 level with a $\beta=0.20$ and expected correlation coefficient of 0.20 requires a total sample size of 194 [32]. A sample size of 97 is required for a multiple regression with a maximum of 8 predictors at the power level of 0.80 and an anticipated 0.15 effect size at the 0.05 probability level [33].

\section{Results}

\section{Demographic Data}

As illustrated in Table 1, respondents were drawn from 42 states in all 4 regions of the U.S. with the majority living in the South or West and in a county in a metro area with a 1 million or more population. The majority of youth were between 16 and 17 years, lived with parents, identified as gay, had 1 guardian with some or more college education, had disclosed their sexual orientation to "most or all people" and to at least one parent/guardian, However, only a third reported that at least one parent/guardian was aware the youth was sexually active. Half self-identified as nonHispanic white, $34 \%$ as Hispanic and approximately $15 \%$ as other racial/ethnic minorities. A MANOVA comparing non-Hispanic white to ethnic minority youth indicated no significant demographic or sexual activity differences with the following exception: Non-Hispanic white youth reported higher levels of primary guardian education than minority youth [Mean $(\mathrm{SD})=4.84(1.2)$ vs $3.99(1.76), \mathrm{F}_{1,171}=13.95$, $\mathrm{p}<0.001$ ] and secondary guardian education [Mean (SD) 4.87 (1.24) vs 3.99 (1.85), $\left.\mathrm{F}_{1,171}=13.49, \mathrm{p}<0.001\right]$. Chi square analyses of dichotomous scores yielded only 1 significant difference: Ethnic minority youth were less likely (60\%) than non-Hispanic white youth $(80 \%)$ to be out to at least one guardian $\left(\mathrm{X}_{1}^{2}=9.016, \mathrm{p}<0.01\right)$.

The majority had on average 3.36 lifetime male anal sex partners. Seventy-four percent of youth reported they had not used a condom or other protective barrier at least once when engaging in sex with another male. Yet, only $29 \%$ believed they were likely to contract HIV. Approximately one-third $(\mathrm{N}=69)$ reported having an HIV test. Of those, 16 (23\%) reported guardian permission had been required for testing. HIV testing was unrelated to whether they reported unprotected anal sex $\left(X_{1,181}^{2}=0.13, n s\right)$ or whether they perceived themselves to be at risk for HIV $\left(\mathrm{r}_{189}=0.09 \mathrm{~ns}\right)$ or worried about HIV $\left(\mathrm{r}_{189}=0.12, \mathrm{~ns}\right)$. Less than half indicated they had received any HIV/STI prevention services from their doctor and that they never received sexual health information helpful to MSM teens during regular medical checkups. Of the 82 youth who had 
Table 1 Frequency and percent of sample responding to items describing demographic characteristics, sexual orientation disclosures, sexual health behaviors, sexual health services and attitudes toward HIV risk

Frequency and percent of sample $(\mathrm{N}=198)$

General demographics

Age

14

$8(4.0 \%)$

15

$27(13.6 \%)$

16

$80(40.4 \%)$

17

$83(41.9 \%)$

Race/ethnicity $(\mathrm{N}=196)$

Black or African American

$9(4.5 \%)$

Asian/Pacific Islander

$10(5.1 \%)$

White

$100(50.5 \%)$

Hispanic/Latino

$68(34.3 \%)$

More than one race

$8(4.0 \%)$

Other

$1(0.5 \%)$

Living with Parents

$194(97.0 \%)$

Highest education of primary parent/guardian $(\mathrm{N}=193)$

High school or less

$60(30.0 \%)$

Some college

$40(20.0 \%)$

College degree

$29(14.5 \%)$

Graduate degree

$64(32.0 \%)$

Highest education secondary parent/guardian $(\mathrm{N}=168)$

High school or less

$55(27.5 \%)$

Some college

$22(11.0 \%)$

College degree

$36(18.0 \%)$

Graduate degree

$55(27.5 \%)$

Geographic region

Northeast

$33(18.5 \%)$

Midwest

$29(16.3 \%)$

South

$58(32.6 \%)$

West

$58(32.6 \%)$

Metro versus non-metro region

Metro (250,000-1,000,000)

$143(81.7 \%)$

Non-metro (20,000-249,000)

$18(10.3 \%)$

Non-metro $(2500-19,999)$

$12(6.9 \%)$

Sexual orientation disclosures

Sexual identity

Gay

$164(82.8 \%)$

Bisexual

$26(13.1 \%)$

Pansexual

$5(2.5 \%)$

Other

$3(1.5 \%)$

Sexual orientation disclosure

Not out to anyone

$1(0.5 \%)$

Only out to a select few people

$42(21.2 \%)$

Out to most people

$76(38.4 \%)$

Out to everyone

$79(39.9 \%)$

Sexual orientation disclosure to parents/guardians

Out to at least one (but not all) parents/guardians 
Table 1 (continued)

\begin{tabular}{|c|c|}
\hline & $\begin{array}{l}\text { Frequency and } \\
\text { percent of sample } \\
(\mathrm{N}=198)\end{array}$ \\
\hline Not out to any parent/guardian & $62(31.3 \%)$ \\
\hline At least one parent/guardian aware adolescent is sexually active & $60(30.3 \%)$ \\
\hline \multicolumn{2}{|l|}{ Sexual Health Behaviors } \\
\hline \multirow[t]{3}{*}{ Number of male anal sexual partners (lifetime) } & $\mathrm{M}=3.36$ \\
\hline & $\mathrm{SD}=4.58$ \\
\hline & Range $=1-35$ \\
\hline \multirow[t]{3}{*}{ Number male anal sexual partners without a condom (lifetime) } & $\mathrm{M}=1.83$ \\
\hline & $\mathrm{SD}=2.96$ \\
\hline & Range $=0-25$ \\
\hline Consumed alcohol or drugs at least once before sexual contact (past year) & $85(43.4 \%)$ \\
\hline \multicolumn{2}{|l|}{ Sexual health services and HIV attitudes } \\
\hline Lifetime HIV testing & $69(34.8 \%)$ \\
\hline Tested for HIV in past year & $64(32.3 \%)$ \\
\hline Tested for STI in past year & $49(24.8 \%)$ \\
\hline Likelihood of HIV Infection (somewhat—extremely) & $29(14.5 \%)$ \\
\hline Worry about HIV Infection (some-all the time)) & $117(58.5 \%)$ \\
\hline Doctor or other healthcare provider asked questions about sexual orientation/attractions (sometimes-always) & $42(21 \%)$ \\
\hline $\begin{array}{l}\text { Comfortable answering doctor or other health care provider's questions about sexual orientation/attractions (some- } \\
\text { what-very comfortable) }\end{array}$ & $33(41.8 \%)$ \\
\hline Doctor helpful about sexual health issues for teens who have sex with male partners. (somewhat-always) & $42(21.0 \%)$ \\
\hline $\begin{array}{l}\text { Discussed or received condoms or other tools to prevent HIV or sexually transmitted infections (STIs) from a health } \\
\text { care provider (sometimes-always) }\end{array}$ & $42(21.0 \%)$ \\
\hline When I go for a general medical check-up, my regular doctor assumes I am heterosexual (sometimes-always) & $162(82.7 \%)$ \\
\hline \multicolumn{2}{|l|}{ Professionals adolescent feels comfortable discussing sexual orientation } \\
\hline Regular pediatrician or family doctor & $57(28.8 \%)$ \\
\hline School counselor or school psychologist & $95(48 \%)$ \\
\hline A psychologist, psychiatrist or other mental health therapist & $71(36 \%)$ \\
\hline
\end{tabular}

received condoms or other HIV/STI prevention tools from a healthcare provider $21(26 \%)$ reported guardian permission had been required. Almost three-quarters of participants believed their doctor assumed they were straight, and only one-third reported that a health care provider had ever asked them about sexual attractions. Of those who had received questions about their sexual attractions, over $40 \%$ reported feeling comfortable answering such questions. Youth were least comfortable discussing sexual orientation with medical doctors (28.8\%) compared with school counselors or mental health professionals (48 and 36\%, respectively).

Pearson Product Moment correlations indicated age did not emerge significant for any of the analyses described below with the following exceptions: older youth had more anal sex experiences with a male partner and were less likely to report their regular health care provider asked them questions about their sexual attractions/orientation $\left(r_{196}=0.15, p<0.05\right.$ and $r_{196}=-0.14, p<0.05$, respectively).

\section{Factor Analysis and Scale Construction}

Across the 22 items relevant to health care experiences and attitudes (Table 4), the number of missing scores for an individual respondent ranged from 0 to 4 items. A factor analysis using Varimax rotation on the 18 items on sexual health communications, medical mistrust, and medical discrimination experiences yielded a 3-factor solution, accounting for $56.90 \%$ of the variance. Factor loadings, item means, percent of respondents endorsing items, and resultant scale mean scores and standard deviations are presented in Table 2. The Sexual Health Communications Scale was constructed from the 6 items loading on Factor 1 (20.86\% variance explained) and yielded good inter-item reliability $(\alpha=0.88)$. None of the items were endorsed as occurring sometimes or always by more than $48 \%$ of respondents thus indicating general lack of communication with physicians regarding the sexual health needs of AMSM.

The AMSM Medical Mistrust Scale was constructed from the 6 items loading on factor 2 (19.03\% variance explained) 
Table 2 Factor loadings, means, standard deviations, and frequency of high endorsement ("often" or "always") for scale items on the Sexual Health Communications Scale, AMSM Medical Mistrust Scale and LGBTQ Medical Discrimination Scale

\begin{tabular}{|c|c|c|c|c|}
\hline \multirow[t]{2}{*}{ Variable } & \multicolumn{3}{|c|}{ Factor loading ${ }^{\mathrm{a}}$} & \multirow{2}{*}{$\begin{array}{l}\text { Total } \\
\mathrm{M}(\mathrm{SD}) \\
N(\%) \text { of } \\
\text { "often" or } \\
\text { "always", }\end{array}$} \\
\hline & $\mathrm{F} 1$ & $\mathrm{~F} 2$ & F3 & \\
\hline Sexual Health Communications Scale $(\alpha=0.88)$ & & & & $1.69(0.85)$ \\
\hline $\begin{array}{l}\text { In the past I have spoken to a doctor, nurse or other healthcare provider about having sex with } \\
\text { male partners }\end{array}$ & 0.818 & -0.196 & -0.017 & $\begin{array}{l}1.63(1.10) \\
62(31.3 \%)\end{array}$ \\
\hline $\begin{array}{l}\text { In the past I have spoken to a doctor, nurse or other healthcare provider about condoms or other } \\
\text { ways to prevent HIV or other sexually transmitted diseases specifically with male sexual part- } \\
\text { ners }\end{array}$ & 0.814 & -0.159 & -0.019 & $\begin{array}{l}1.64(1.09) \\
66(33.3 \%)\end{array}$ \\
\hline $\begin{array}{l}\text { In the past I have spoken to a doctor, nurse or other healthcare provider about my sexual orienta- } \\
\text { tion }\end{array}$ & 0.805 & -0.192 & -0.039 & $\begin{array}{l}1.86(1.23) \\
85(42.9 \%)\end{array}$ \\
\hline $\begin{array}{l}\text { In the past I have spoken to a doctor, nurse or other healthcare provider about condoms or other } \\
\text { ways to prevent HIV or other sexually transmitted diseases }\end{array}$ & $\mathbf{0 . 7 5 0}$ & -0.187 & 0.051 & $\begin{array}{l}2.08(1.24) \\
105(46.7 \%)\end{array}$ \\
\hline In the past I have spoken to a doctor, nurse or other healthcare provider about HIV testing & 0.746 & -0.213 & 0.063 & $\begin{array}{l}1.73(1.10) \\
78(39.4 \%)\end{array}$ \\
\hline $\begin{array}{l}\text { In the past I have spoken to a doctor, nurse or other healthcare provider about taking a pill called } \\
\text { PrEP (e.g. Truvada) to prevent HIV infection }\end{array}$ & 0.699 & 0.001 & -0.034 & $\begin{array}{l}1.21(0.73) \\
20(10.1 \%)\end{array}$ \\
\hline AMSM Medical Mistrust Scale $(\alpha=0.85)$ & & & & $2.47(1.18)$ \\
\hline $\begin{array}{l}\text { I avoided asking questions about my sexual health because I did not want a healthcare provider or } \\
\text { staff member to know that my sexual partners were male }\end{array}$ & -0.167 & 0.788 & 0.169 & $\begin{array}{l}2.62(1.54) \\
125(63.1 \%)\end{array}$ \\
\hline $\begin{array}{l}\text { I avoided asking questions about my sexual health because I did not want a healthcare provider or } \\
\text { staff member to know that I was LGBTQ }\end{array}$ & -0.130 & 0.778 & 0.214 & $\begin{array}{l}2.51(1.54) \\
117(59.1 \%)\end{array}$ \\
\hline $\begin{array}{l}\text { When I go for a regular medical check-up with my regular pediatrician or family doctor, I do not } \\
\text { discuss sexual issues because I worry my doctor will not be accepting of my sexual orientation }\end{array}$ & -0.176 & 0.728 & 0.167 & $\begin{array}{l}2.61(1.50) \\
130(66.7 \%)\end{array}$ \\
\hline $\begin{array}{l}\text { When I go for a general medical check-up with my regular pediatrician or family doctor, I do not } \\
\text { ask for information about condoms or other ways to prevent HIV or STIs because I worry that } \\
\text { my doctor would tell my parents about my sexual orientation }\end{array}$ & -0.230 & 0.706 & 0.071 & $\begin{array}{l}2.61(1.70) \\
107(54.3 \%)\end{array}$ \\
\hline $\begin{array}{l}\text { I avoided getting tested for HIV or an STI because I was worried that I would be "outed" or } \\
\text { criticized for being LGBTQ }\end{array}$ & -0.069 & 0.666 & 0.251 & $\begin{array}{l}1.95(1.42) \\
74(37.5 \%)\end{array}$ \\
\hline $\begin{array}{l}\text { When I go for a general medical check-up with my regular pediatrician or family doctor, I do not } \\
\text { ask for information about condoms or other ways to prevent HIV or STIs because I worry that } \\
\text { my doctor would tell my parents I was sexually active }\end{array}$ & -0.156 & 0.638 & -0.023 & $\begin{array}{l}3.24(1.64) \\
137(69.2 \%)\end{array}$ \\
\hline LGBTQ Medical Discrimination Scale $(\alpha=0.79)$ & & & & $1.12(0.37)$ \\
\hline A healthcare provider or staff member criticized or insulted me for being LGBTQ & 0.046 & -0.027 & 0.853 & $\begin{array}{l}1.07(0.35) \\
8(4.0 \%)\end{array}$ \\
\hline I felt discriminated against by a healthcare provider or staff member because I was LGBTQ & 0.068 & 0.052 & 0.739 & $\begin{array}{l}1.16(0.58) \\
18(9.1 \%)\end{array}$ \\
\hline I received poor medical treatment because I am LGBTQ & -0.051 & 0.142 & 0.664 & $\begin{array}{l}1.08(0.43) \\
7(3.5 \%)\end{array}$ \\
\hline $\begin{array}{l}\text { A healthcare provider or staff member made negative comments about people who are LGBTQ } \\
\text { people }\end{array}$ & -0.033 & 0.086 & 0.657 & $\begin{array}{l}1.17(0.61) \\
19(9.6 \%)\end{array}$ \\
\hline $\begin{array}{l}\text { I did not receive the sexual health information I needed because a healthcare provider or staff } \\
\text { member disapproved of people who are LGBTQ }\end{array}$ & 0.005 & 0.233 & 0.632 & $\begin{array}{l}1.15(0.57) \\
15(7.6 \%)\end{array}$ \\
\hline $\begin{array}{l}\text { I did not receive the sexual health information I needed because the healthcare provider or staff } \\
\text { disapproved of teenagers having sex }\end{array}$ & -0.021 & 0.230 & 0.578 & $\begin{array}{l}1.36(0.87) \\
36(18.2 \%)\end{array}$ \\
\hline
\end{tabular}

The bolded numbers indicate the primary factor on which the item loaded

${ }^{a} \mathrm{KMO}$ measure of sampling $=818$; Bartlett's test of sphericity $(\mathrm{df} 153)=1670.64, \mathrm{p}<0.001$

${ }^{\mathrm{b}} 1=$ never, $2=$ rarely, $3=$ sometimes, $4=$ often, $5=$ always

reflecting avoidance of HIV testing and communications with providers about sexual orientation and behaviors due to fear of sexual minority stigma and disclosure of confidential information to parents. The scale yielded good inter-item reliability $(\alpha=0.85)$. All items were endorsed by over $50 \%$ of respondents suggesting mistrust as a critical barrier to 
communications about HIV/STI prevention with providers. The LGBTQ Medical Discrimination Scale was constructed from the 6 items loading on factor $3(17.01 \%$ variance explained). This scale reflected the youth's direct experiences of sexual minority related discrimination by health care providers and yielded acceptable inter-item reliability $(\alpha=0.79)$. The percent of youth endorsing these items was consistently low indicating few direct experiences with sexual minority discrimination in health care settings.

A second factor analysis on the four items modified to reflect LGBTQ equitable treatment in health care settings [31] yielded a single factor accounting for $72.75 \%$ of the variance (see Table 3). The LGBTQ Health Equity Scale constructed from these 4 items yielded an inter-item reliability of $\alpha=0.87$. Percent endorsement of items ranged from 45.5 to $55.8 \%$ suggesting only half of the respondents believed sexual minority patients received the same medical care as heterosexual patients. A MANOVA yielded no significant differences between non-Hispanic white and ethnic minority youth on the 4 scales (Wilkes Lambda $=0.02, \mathrm{~F}_{4,181}=1.31$, $\mathrm{p}=0.26$ ). Across scale scores, Pearson Product Moment correlations indicated age was only significantly correlated with the LGBTQ Health Equity scale $(r=0.14, p<0.05)$.

\section{Relationship Among Scales and Other Variables}

Table 4 provides correlations among scale scores and single items related to sexual healthcare, sexual behavior, and

Table 3 Factor loadings, means, standard deviations, frequency and percent agreement ("somewhat agree" or "strongly agree") for LGBTQ health equity items

\begin{tabular}{|c|c|c|c|}
\hline & Factor loading & Mean (SD) & $\mathrm{N}(\%)$ \\
\hline LGBTQ health equity scale $(\alpha=0.87)$ & & $3.30(1.02)$ & \\
\hline $\begin{array}{l}\text { LGBTQ people receive the same medical care from doctors and health care workers as people } \\
\text { from other groups }\end{array}$ & 0.90 & $3.19(1.25)$ & $91(46 \%)$ \\
\hline LGBTQ people are treated the same as people of other groups by doctors and health care workers & 0.90 & $3.17(1.19)$ & $90(45.5 \%)$ \\
\hline In most hospitals people with different sexual identities receive the same kind of care & 0.85 & $3.42(1.19)$ & $108(55.8 \%)$ \\
\hline Doctors have the best interest of LGBTQ people in mind & 0.75 & $3.41(1.13)$ & $100(51.5 \%)$ \\
\hline
\end{tabular}

$\mathrm{KMO}=0.799 ;$ Bartlett's test of sphericity $(6)=426.94, \mathrm{p}<0.001$

Table 4 Pearson product moment correlations among scale scores and with individual items reflecting sexual health services, sexual behaviors, and disclosures to parents

\begin{tabular}{|c|c|c|c|c|c|c|c|}
\hline & 1 & 2 & 3 & 4 & 5 & 6 & 7 \\
\hline $\begin{array}{l}\text { 1. Sexual health communi- } \\
\text { cations scale }\end{array}$ & - & - & - & - & - & - & - \\
\hline $\begin{array}{l}\text { 2. AMSM medical mistrust } \\
\text { scale }\end{array}$ & $-0.40 * * *(192)$ & - & - & - & - & - & - \\
\hline $\begin{array}{l}\text { 3. LGBTQ medical discrim- } \\
\text { ination scale }\end{array}$ & $-0.03(196)$ & $0.35 * * *(193)$ & - & - & - & - & - \\
\hline $\begin{array}{l}\text { 4. LGBTQ health equity } \\
\text { scale }\end{array}$ & $0.14(193)$ & $-0.33^{* * *}(189)$ & $-0.38 * * *(193)$ & - & - & - & - \\
\hline $\begin{array}{l}\text { 5. Healthcare provider } \\
\text { asked about sexual attrac- } \\
\text { tions/orientation }\end{array}$ & $0.60 * * *(197)$ & $-0.18^{*}(193)$ & $-0.06(197)$ & $0.12(194)$ & - & - & - \\
\hline $\begin{array}{l}\text { 6. Frequency discussing } \\
\text { or receiving condoms or } \\
\text { other tools to prevent HIV } \\
\text { or STIs from health care } \\
\text { provider }\end{array}$ & $0.57 * * *(197)$ & $-0.38 * *(193)$ & $-0.01(197)$ & $0.18 *(194)$ & $0.29 * *(198)$ & - & - \\
\hline 7. HIV testing (lifetime) & $0.56 * * *(189)$ & $-0.31 * *(184)$ & $-0.03(188)$ & $0.05(185)$ & $0.34 * * *(189)$ & $0.36 * * *(198)$ & - \\
\hline $\begin{array}{l}\text { Number of lifetime male } \\
\text { anal sex partners }\end{array}$ & $0.34 * * *(197)$ & $-0.17 *(193)$ & $0.02(197)$ & $0.11(194)$ & $0.17(196)$ & $0.10(198)$ & $0.29 * * *(189)$ \\
\hline Out to at least one parent & $0.17 *(196)$ & $-0.42 * * *(192)$ & $-0.03(196)$ & $0.10(193)$ & $0.01(196)$ & $-0.07(199)$ & $0.12(189)$ \\
\hline $\begin{array}{l}\text { At least one guardian aware } \\
\text { adolescent sexually active }\end{array}$ & $0.20 * *(197)$ & $-0.20 * *(193)$ & $-0.05(198)$ & $0.10(193)$ & $0.08(189)$ & $0.16^{*}(198)$ & $0.14(189)$ \\
\hline
\end{tabular}

$* \mathrm{p} \leq 0.05, * * \mathrm{p} \leq 0.01, * * * \mathrm{p} \leq 0.001$ 
family disclosures. As hypothesized, higher scores on the Sexual Health Communications Scale were negatively correlated with AMSM Medical Mistrust and positively correlated with whether healthcare providers asked questions about youth's sexual attractions/orientation, receipt of HIV/ STI preventive services, and HIV testing. Youth with higher Sexual Health Communications scores were also significantly more likely to have a greater number of lifetime male sex partners and to have disclosed their sexual orientation and sexual activity to at least one guardian.

Relationships among variables were in the opposite direction for the AMSM Medical Mistrust Scale. As hypothesized medical mistrust was positively related to personal experiences with discrimination as measured by the LGBTQ Medical Discrimination Scale. Medical mistrust was negatively related to Sexual Health Communications and the LGBTQ Health Equity scales and to single items indicating a healthcare provider had asked questions about their sexual orientation, receipt of HIV/STI preventive services, lifetime HIV testing, number of lifetime male anal sex partners, and sexual orientation and sexual activity disclosures to guardians. Personal experiences with discrimination as assessed by the LGBTQ Medical Discrimination Scale were negatively associated with general perceptions of sexual minority equity in health care settings.

As illustrated in Table 4, the frequency with which youth received condoms or other HIV/STI preventive information or tools from providers was positively correlated with whether a provider asked questions about MSM attraction/ sexual orientation, number of male anal sex partners and whether youth had been tested for HIV. Similarly, HIV testing was significantly and positively correlated with whether a doctor asked questions about youth's sexual orientation, youth's HIV relevant communications with providers, number of male anal sex partners, and having at least one guardian who probably or definitely knew the youth was sexually active. HIV testing was negatively associated with higher scores on the AMSM Medical Mistrust scale. Youth's beliefs about whether they were likely to acquire or worry about HIV acquisition were not significantly associated with any scale scores, receipt of sexual health services, family disclosure, or sexual behavioral variables.

\section{Regression Analyses}

Two multiple linear regressions were conducted to assess cumulative and independent influences of variables correlated with Sexual Health Communications and frequency of receipt of HIV/STI prevention tools. The first analysis regressed Medical Mistrust, practitioner questions about sexual attraction/orientation, number of male anal sexual partners, age and sexual orientation and sexual behavior disclosures to parents onto the Sexual Health Communications
Scale and yielded an $\mathrm{R}^{2}=0.37\left(\mathrm{~F}_{6,183}=17.92, \mathrm{p}<0.001\right.$; Durban-Watson $=1.56$ ). Significant Beta scores indicated independent influences when other factors were held constant for LGBTQ Medical Mistrust $(\beta=-0.31 ; \mathrm{t}=-4.66$, $\mathrm{p}<0.001$ ), whether provider asked questions about sexual attraction/orientation $(\beta=0.33 ; \mathrm{t}=5.45, \mathrm{p}<0.001)$.and number of male anal sex partners $(\beta=0.23 ; t=3.84, p<0.001)$.

A second multiple regression was performed with LGBTQ Medical Mistrust, LGBTQ Health Equity, provider questions about sexual attraction/orientation, age and guardian awareness of sexual activity on the frequency of youth receiving sexual health information and tools specific to HIV/STI. This analysis yielded an $\mathrm{R}^{2}=0.22\left(\mathrm{~F}_{5,182}=10.37\right.$, $\mathrm{p}<0.001$; Durban-Watson $=2.05$ ). Beta scores indicating independent influences when other factors were held constant were significant for LGBTQ Medical Mistrust $(\beta=-0.34 ; \mathrm{t}=-4.81, \mathrm{p}<0.001)$ and whether the adolescent's doctor had ever asked about sexual orientation or attractions $(\beta=0.23 ; \mathrm{t}=3.46, \mathrm{p}<0.01)$.

A logistic regression was performed to ascertain the effects of Sexual Health Communications, LGBTQ Medical Mistrust, provider questioning about sexual attractions/ orientation, age and number of male anal sex partners on the likelihood that participants had received an HIV test. The logistic regression model was significant, $\mathrm{X}_{5}^{2}=78.39$, $\mathrm{p}<0.001$. The model explained 33\% of the variance (Nagelkerke $\mathrm{R}^{2}$ ) and correctly classified $62 \%$ of the cases. Beta scores indicating independent influences when other factors were held constant were significant for Sexual Health Communications $\left(\beta=2.10 ; \mathrm{W}_{1}=27.64, \mathrm{p}<0.001\right)$ and number of male anal sex partners $\left(\beta=0.14 ; \mathrm{W}_{1}=4.70, \mathrm{p}<0.05\right)$.

\section{Discussion}

Adolescent males who have sex with males are a key population at risk for HIV [34, 35]. Affirming and competent HIV/ STI prevention services specific to the needs and experiences of MSM adolescents are critical to ensuring the health and safety of this vulnerable population. However, accomplishing this requires a context that engenders patient trust and a willingness to share sexual information with physicians. To our knowledge this is the first study specifically identifying healthcare experiences and concerns, perceptions, sexual behavior, and familial factors influencing receipt of MSM sensitive sexual health care communications and services for youth 14-17 years of age.

Many AMSM in our study endorsed items indicating they did not discuss their sexual orientation with their health care provider and avoided getting HIV/STI testing because they worried they would be outed or stigmatized. This finding suggests that communication barriers to sexual health services tied to anticipated heterosexist bias documented among 
older sexual minority patients $[9,15-19,21]$ begins as early as 14 years of age. Importantly, we found that youth who reported that a provider had asked them questions about their sexual attractions or orientation reported higher levels of sexual health care communications and receipt of HIV and STI preventive services, including HIV testing. Although most had not had direct experiences with heterosexist discrimination in medical settings, more than half believed that LGBTQ patients received inequitable treatment in health care settings. These experiences and beliefs were associated with higher levels of anticipated stigma as measured by items on the AMSM Medical Mistrust scale and lower levels on single items reflecting HIV provider communications, services and HIV testing.

Unlike MSM 18 years and older who have adult legal status, 14-17 year old MSM must also consider whether a doctor will tell parents about what is discussed during medical visits [36, 37]. In our sample, almost half avoided discussing their sexual orientation and behaviors because they feared their health care provider would disclose such information to parents. Although this concern was particularly salient among youth who were not out to parents, our data indicate that providers should not conclude that parents who are aware of their son's sexual orientation identity are accepting of the patient's sexual orientation or behaviors nor that youth who are out would be unconcerned about their physician sharing such information with parents. These results contribute to a limited but growing empirical literature on the complex relationship between parental support and health among sexual minority adolescents [29, 30, 35, 38-40]. While some research suggests that parental support for youth who disclosed their sexual orientation is associated with better health results [41, 42], other research suggests that parental monitoring of and communication about samesex sexual activity may actually be associated with increased sexual risk behaviors [43].

The majority of adolescents in our sample had at least one experience with unprotected anal sex with a male partner. Yet, most did not think they were at risk for HIV nor had they received HIV testing. Youth were significantly more likely to receive HIV/STI prevention information and services from a doctor within the past year if the healthcare professional had asked them about their sexual attractions or orientation. However, consistent with previous research (e.g. [44]), adolescents in our sample did not view doctors as a primary source of sexual health information. These findings may have implications for AMSM, who may not have access to other sources of sexual health information specific to their needs. For example, hetero-normative sexual health curricula and the paucity of educational and other resources specific to sexual minority youth $[21,45,46]$ likely limit AMSM's knowledge and implementation of HIV/STI prevention strategies.

\section{Limitations}

Our online data collection and recruitment methods yielded a national sample of sexually active AMSM, and the anonymous online method of the questionnaire may have increased participant comfort and encouraged honest and candid answering. However, as with most online studies, we cannot claim with certainty that respondents actually met the inclusion criteria and, aside from word-of-mouth promotion from other MSM adolescents, recruitment was limited to those who use Facebook, have access to the Internet or mobile phones and who frequent sexual minority social media sites [47]. Almost one-third of our sample self-identified as Hispanic and an additional 15\% identified as either Black/ African American, Asian/Pacific Islander or more than one race. Few differences between non-Hispanic white and members of other ethnic groups emerged. However, there were insufficient respondents from non-Hispanic ethnic minority groups to examine issues related to how the intersectionality of ethnic and sexual minority status may influence motivation to participate in HIV research; an important area for future research $[9,48]$. In addition, almost all youth lived with their parents, the majority of whom had at least some college education. Thus, our study may not have captured the views of youth from impoverished, family abandoned, or homeless situations who may be engaged in sex work or other sexual behaviors who would most benefit from prevention strategies based on empirical studies tailored to their lived experience. Finally, given the dual sexual and gender minority status of transgender youth, we limited recruitment to MSM youth who had a male sex assigned at birth. As part of the larger study we are in the process of analyzing a separate set of data on sexual health care experiences of young transgender females.

\section{Conclusion}

This study explored concerns, attitudes and experiences related to HIV/STI prevention services among sexually active adolescent MSM 14-17 years of age. To accomplish this, we developed psychometrically valid scales that can be used for future research exploring the relationship between AMSM HIV health disparities and communications with providers, medical mistrust, and medical discrimination and anticipated sexual minority stigma. Using these measures, we found that the majority of sexually active youth had neither discussed nor received HIV/ STI prevention tools from their healthcare providers. Fear of being outed or rejected by medical staff was a primary reason for avoiding discussion of sexual health concerns. Given the reluctance to reveal their sexual orientation, it is not surprising that few youth reported 
personal experiences with sexual minority discrimination by health care professionals. Yet, their overarching belief that LGBTQ people did not receive the same quality of care as other groups in medical settings emerged as an impediment to HIV testing and requesting HIV/STI information and preventive tools from health practitioners.

While health care providers may be in a unique position to discuss safer sexual practices specific to sex among male partners, only $20 \%$ of youth reported that a healthcare provider had asked them questions about their sexual orientation or attractions. These findings are consistent with reports by physicians that they do not regularly discuss sexual orientation or attractions with patients due to insufficient training in taking sexual histories and widely held misconception that patients would refuse to answer or be offended by questions related to their sexual orientation [2, 9, 49-53]. In contrast, consistent with surveys of older LGBTQ patients, almost half our participants indicated they would be comfortable answering physician questions regarding their sexual orientation [54, 55]. Given the increased HIV and STI risk among AMSM, health care providers cannot afford to wait for young patients to raise the subject, since as our study and prior research indicates adolescents often do not disclose information critical to sexual health for fear of practitioner bias and do not view health care providers as a primary source for sexual health information [29, 44, 46, 56].

Results from this study also highlight the requisite importance of patient trust in seeking and receiving sexual health care services and draw attention to the concerns of AMSM regarding confidentiality and disclosure to parents. Health care providers may struggle with balancing adolescent expectations for confidentiality regarding their sexual behaviors and parental rights to be informed [36]. Yet, as our results suggest, fear of being outed to family may be a significant barrier to sexual health communications. This finding underscores the need for physician sensitivity to youth's privacy concerns and for communication practices that include discussing with MSM youth their commitment to patient confidentiality rights. Enhanced sexual minority based training for pediatricians and primary care physicians who are often the initial gateway to youth's safer sex practices can create positive early health care experiences that set the stage for AMSM's future interactions with health care professionals and their sexual health.

Acknowledgements The authors thank Margaret Desmond and Leah Puri for assistance on data analysis and manuscript preparation. They also thank the participants who generously gave their time and from whom the authors learned so much.

Funding The research reported and preparation of this article were supported on a Grant from the National Institute on Minority Health and Health Disparities at the National Institutes of Health under Award Number 1 R01 MD009561 (PIs Celia B. Fisher and Brian Mustanski).

\section{Compliance with Ethical Standards}

Conflicts of interest The authors do not have any conflicts of interest.

Ethical Approval This human subjects research received Institutional Review Board approval from Fordham University and Northwestern University. Informed consent was obtained from all participants. All procedures performed in this research are in accordance with U.S. regulations and the 1964 Helsinki declaration and later amendments.

\section{References}

1. Center for Disease Control. Sexual indentity, sex of sexual contacts, and health-related behaviors among students in grades 9-12-United States and selected sites, 2015; 2016.

2. Coker TR, Schuster MA, Austin SB. The health and health care of lesbian, gay, and bisexual adolescents. Annu Rev Public Health. 2010;31:457-77.

3. Herrick AL, Smith HA, Stall RD, Marshal MP, Sucato G. Sex while intoxicated: a meta-analysis comparing heterosexual and sexual minority youth. J Adolesc Health. 2011;48(3):306-9.

4. Kann L, Olsen EOM, McManus T, et al. Sexual identity, sex of sexual contacts, and health-related behaviors among students in grades 9-12-United States and selected sites, 2015. MMWR Surveill Summ. 2016;65(9):1-202.

5. Milhausen RR, McKay A, Graham CA, Crosby RA, Yarber WL, Sanders SA. Prevalence and predictors of condom use in a national sample of Canadian university students. Can J Hum Sex. 2013;22(3):142-51.

6. Center for Disease Control. HIV among gay and bisexual men; 2017.

7. Jackson CL, Agnnor M, Johnson DA, Austin SB, Kawachi I. Sexual orientation identity disparities in health behaviors, outcomes, and services use among men and women in the United States: a cross-sectional study. BMC Public Health. 2016;1:807.

8. Institute of Medicine, Committee on Lesbian GB, Transgender Health I, Research G, Opportunities. The health of lesbian, gay, bisexual, and transgender people: building a foundation for better understanding. Washington DC: National Academies Press. 2011.

9. MacApagal K, Greene GJ, Bhatia R. Differences in healthcare access, use, and experiences within a community sample of racially diverse lesbian, gay, bisexual, transgender, and questioning emerging adults. LGBT Health. 2016;3(6):434-42.

10. Philbin MM, Tanner AE, DuVal A, et al. Factors affecting linkage to care and engagement in care for newly diagnosed HIVpositive adolescents within fifteen adolescent medicine clinics in the United States. AIDS Behav. 2014;18(8):1501-10.

11. Phillips G, Ybarra ML, Prescott TL, Parsons JT, Mustanski B. Low rates of human immunodeficiency virus testing among adolescent gay, bisexual, and queer men. J Adolesc Health. 2015;4:407.

12. Strutz KL, Herring AH, Halpern CT. Health disparities among young adult sexual minorities in the U.S. Am J Prev Med. 2015;48(1):76-88.

13. Williams KA, Chapman MV. Comparing health and mental health needs, service use, and barriers to services among sexual minority youths and their peers. Health Soc Work. 2011;36(3):197-206.

14. Zanoni BC, Mayer KH. The adolescent and young adult HIV cascade of care in the United States: exaggerated health disparities. AIDS Patient Care STDs. 2014;28(3):128-35.

15. Eaton LA, Driffin DD, Kegler C, et al. The role of stigma and medical mistrust in the routine health care engagement of black men who have sex with men. Am J Public Health. 2015;105(2):e75-82. 
16. Rounds KE, McGrath BB, Walsh E. Perspectives on provider behaviors: a qualitative study of sexual and gender minorities regarding quality of care. Contemp Nurse. 2013;44(1):99-110.

17. Meanley S, Gale A, Harmell C, Jadwin-Cakmak L, Pingel E, Bauermeister JA. The role of provider interactions on comprehensive sexual healthcare among young men who have sex with men. AIDS Educ Prev. 2015;27(1):15-26.

18. Rossman K, Salamanca P, Macapagal K. A qualitative study examining young adults' experiences of disclosure and nondisclosure of LGBTQ identity to health care providers. J Homosex. 2017;10:1390.

19. Wall KM, Khosropour CM, Sullivan PS. Offering of HIV screening to men who have sex with men by their health care providers and associated factors. JIAPAC. 2010;9(5):284.

20. Hoffman ND, Freeman K, Swann S. Healthcare preferences of lesbian, gay, bisexual, transgender and questioning youth. J Adolesc Health. 2009;45(3):222-9.

21. Arbeit MR, Fisher CB, Macapagal K, Mustanski B. Bisexual invisibility and the sexual health needs of adolescent girls. LGBT Health. 2016;3(5):342-9.

22. Hoyt MA, Rubin LR, Nemeroff CJ, Lee J, Huebner DM, Proeschold-Bell RJ. HIV/AIDS-related institutional mistrust among multiethnic men who have sex with men: effects on HIV testing and risk behaviors. Health Psychol. 2012;31(3):269-77.

23. Meckler GD, Elliott MN, Kanouse DE, Schuster MA, Beals KP. Nondisclosure of sexual orientation to a physician among a sample of gay, lesbian, and bisexual youth. Arch Pediatr Adolesc Med. 2006;160(12):1248-54.

24. Williams KA, Chapman MV. Unmet health and mental health need among adolescents: the roles of sexual minority status and child-parent connectedness. Am J Orthopsychiatr. 2012;82(4):473-81

25. Konstan JA, Rosser BRS, Stanton J, Edwards WM, Ross MW. The story of subject naught: a cautionary but optimistic tale of internet survey research. J Comput Mediat Commun. 2005;10(2):5.

26. Bauermeister JA, Pingel E, Zimmerman M, Strecher VJ, Couper M, Carballo-Diéguez A. Data quality in HIV/AIDS web-based surveys: handling invalid and suspicious data. Field Methods. 2012;24(3):272-91.

27. Napper L, Fisher D, Reynolds G. Development of the perceived risk of HIV scale. AIDS Behav. 2012;16(4):1075.

28. D'Augelli AR, Hershberger SL, Pilkington NW. Lesbian, gay, and bisexual youth and their families: disclosure of sexual orientation and its consequences. Am J Orthopsychiatr. 1998;68(3):361-71.

29. Fisher CB, Arbeit MR, Dumont MS, Macapagal K, Mustanski B. Self-consent for HIV prevention research involving sexual and gender minority youth. J Empir Res Hum Res Ethics. 2016;11(1):3.

30. Fisher CB, Fried AL, Desmond M, Macapagal K, Mustanski B. Facilitators and barriers to participation in PrEP HIV prevention trials involving adolescent and emerging adult transgender men and women. AIDS Educ Prev. 2017;29(3):205-17.

31. Shelton RC, Winkel G, Davis SN, et al. Validation of the groupbased medical mistrust scale among urban black men. JGIM. 2010;25(6):549.

32. Hulley SBCS, Browner WS, Grady D, Newman TB. Designing clinical research : an epidemiologic approach. Philadelphia: Lippincott Williams \& Wilkins; 2013. p. 79.

33. Soper DS. A priori sample size calculator for multiple regression [Software]. 2018; http://www.danielsoper.com/statcalc, 2018

34. Council P. Key populations at risk for HIV; 2017.

35. Mustanski BS, Newcomb ME, Bois SND, Garcia SC, Grov C. HIV in young men who have sex with men: a review of epidemiology, risk and protective factors, and interventions. J Sex Res. 2011;2-3:218.

36. Byczkowski TL, Kollar LM, Britto MT. Family experiences with outpatient care: do adolescents and parents have the same perceptions? J Adolesc Health. 2010;47(1):92-8.

37. Ginsburg KR, Slap GB, Cnaan A, Forke CM, Balsley CM, Rouselle DM. Adolescents' perceptions of factors affecting their decisions to seek health care. JAMA. 1995;273(24):1913-8.

38. Diclemente RJ, Sales JM, Ruiz MS. Barriers to adolescents' participation in HIV biomedical prevention research. J Acquir Immune Defic Syndr. 2010;54(SUPPL. 1):S12-7.

39. Gilbert AL, Knopf AS, Fortenberry JD, Hosek SG, Kapogiannis BG, Zimet GD. Adolescent self-consent for biomedical human immunodeficiency virus prevention research. J Adolesc Health. 2015;1:113.

40. Mustanski B, Coventry R, Macapagal K, Arbeit MR, Fisher CB Sexual and gender minority adolescents' views on HIV research participation and parental permission: a mixed-methods study. Perspect Sex Reprod Health. 2017;49(2):111-21.

41. D'Amico E, Julien D. Disclosure of sexual orientation and gay, lesbian, and bisexual youths' adjustment: associations with past and current parental acceptance and rejection. J GLBT Fam Stud. 2012;8(3):215-42.

42. Rothman EF, Sullivan M, Keyes S, Boehmer U. Parents' supportive reactions to sexual orientation disclosure associated with better health: results from a population-based survey of LGB adults in Massachusetts. J Homosex. 2012;59(2):186-200.

43. Thoma BC, Huebner DM. Parental monitoring, parent-adolescent communication about sex, and sexual risk among young men who have sex with men. AIDS Behav. 2014;18(8):1604-14.

44. Donaldson AA, Ellen JM, Marcell AV, Lindberg LD. Receipt of sexual health information from parents, teachers, and healthcare providers by sexually experienced U.S. adolescents. J Adolesc Health. 2013;53(2):235-40.

45. Greene G, Fisher K, Kuper L, Andrews R, Mustanski B. 'Is this normal? is this not normal? there is no set example': sexual health intervention preferences of LGBT youth in romantic relationships. Sex Res Soc Policy. 2015;12(1):1.

46. Charest M, Kleinplatz PJ, Lund JI. Sexual health information disparities between heterosexual and LGBTQ + young adults: implications for sexual health. Can J Hum Sex. 2016;25(2):74-85.

47. Miner MH, Bockting WO, Romine RS, Raman S. Conducting internet research with the transgender population: reaching broad samples and collecting valid data. Soc Sci Comput Rev. 2012;30(2):202-11.

48. Smalley KB, Warren JC, Barefoot KN. Differences in health risk behaviors across understudied LGBT subgroups. Health Psychol. 2016;35:103-14.

49. Kitts RL. Barriers to optimal care between physicians and lesbian, gay, bisexual, transgender, and questioning adolescent patients. J Homosex. 2010;6:730.

50. Dahan R, Feldman R, Hermoni D. Is patients' sexual orientation a blind spot of family physicians? J Homosex. 2008;55(3):524-32.

51. Wittenberg A, Gerber J. Recommendations for improving sexual health curricula in medical schools: results from a two-arm study collecting data from patients and medical students. J Sex Med. 2009;6(2):362-8.

52. Frankowski BL. Sexual orientation and adolescents. Pediatrics. 2004;6:1827.

53. Khalili J, Diamant AL, Leung LB. Finding the perfect doctor: Identifying lesbian, gay, bisexual, and transgender-competent physicians. Am J Public Health. 2015;105(6):1114-9.

54. Haider AH, Schneider EB, Adler RR, et al. Emergency department query for patient-centered approaches to sexual orientation 
and gender identity. The EQUALITY study. JAMA Intern Med. 2017;177(6):819-28.

55. Maragh-Bass AC, German D, Torain M, et al. Risks, benefits, and importance of collecting sexual orientation and gender identity data in healthcare settings: a multi-method analysis of patient and provider perspectives. LGBT Health. 2017;4(2):141-52.

56. Whitfield C, Jomeen J, Hayter M, Gardiner E. Sexual health information seeking: a survey of adolescent practices. J Clin Nurs. 2013;22:3259-69. 